University of Montana

ScholarWorks at University of Montana

Summer 1989

\title{
Socialization Turning Points : An Examination of Change in Organizational Identification
}

Connie Bullis

University of Utah, Salt Lake City, UT

Betsy Bach

University of Montana - Missoula, betsy.bach@umontana.edu

Follow this and additional works at: https://scholarworks.umt.edu/communications_pubs

Part of the Communication Commons

Let us know how access to this document benefits you.

\section{Recommended Citation}

Bullis, Connie and Bach, Betsy, "Socialization Turning Points : An Examination of Change in Organizational Identification" (1989). Communication Studies Faculty Publications. 3.

https://scholarworks.umt.edu/communications_pubs/3

This Article is brought to you for free and open access by the Communication Studies at ScholarWorks at University of Montana. It has been accepted for inclusion in Communication Studies Faculty Publications by an authorized administrator of ScholarWorks at University of Montana. For more information, please contact

scholarworks@mso.umt.edu. 


\section{Socialization Turning Points: An Examination of Change in Organizational Identification}

\section{CONNIE BULLIS and BETSY WACKERNAGEL BACH}

This report identifies a gap between theory and research which plagues two areas of organizational inquiry, describes a method through which these concerns may be addressed, and describes a study which employed this method. Specifically, recent conceptualizations of organizational socialization and organizational identification view individuals as active participants in their relationships with organizations. Yet, research in both areas has over-emphasized the organization's perspective and under-emphasized the individual's. Turning point analysis is a method through which researchers may "listen" to participants' points of view. It was used in a study reported here in order to help round out the relevant bodies of research. Retrospective interviewing was used to reconstruct the history and process of individuals' socialization experiences over an eight-month period. Fifteen types of turning points were identifjed. The results derived from turning point analysis are compared with conceptualizations of socialization and identification. Similarities and differences are noted, and implications are discussed. ${ }^{3}$

$\mathrm{R}$ ECENT RESEARCH HAS EXAMINED a wide variety of topics in the study of organizational socialization (Cheney, 1987a; Falcione \& Wilson, 1988; Feldman, 1988; Jablin, 1987; Kreps, 1983; Reichers, 1987; Stohl, 1986). Yet in elaborating the development of relationships between individuals and organizations, one fundamental dimension along which the process takes place, identification (Burke, 1950; Tompkins, Fisher, Infante \& Tompkins, 1975; Tompkins \& Cheney, 1985), has typically been ignored. In this report, we explain the need to study identification during organizational socialization, offer turning point analysis as a method for examining change during the process, and report results from an initial study.

\section{SOCIALIZATION}

Scholars conceptualize organizational socialization in three primary ways. First, conceptualizations have increasingly highlighted active

CONNIE BULLIS is an Assistant Professor, Department of Communication, University of Utah, Salt Lake City, UT 84112. BETSY WACKERNAGEL BACH is an Assistant Professor, Department of Interpersonal Communication, University of Montana, Missoula, MT 59812. 
participation by organizational newcomers. Historically, organizational socialization scholarship suffered from importing anthropological assumptions. Newcomers to organizations were cast as infant members of societies. For example, Buchanan (1974) discussed the need to understand the processes by which "committed managers are molded" and noted ". . the fact that new managers are tabula rasa insofar as the organization is concerned" (pp. 534-535). As the sociological distinction between primary (infants in societies) and secondary (adults in organizations within societies) socialization was adopted, approaches to organizational socialization attributed more bi-directionality to the individualorganizational relationship. For example, Jablin (1982) adopted the term "assimilation" to characterize socialization and individualization as reciprocal processes through which organizations and individuals develop relationships. Individuals were cast in the role of actively learning the values, norms and behaviors required of them (Brim, 1966; Brown, 1985; Darling, 1986; Jablin \& Krone, 1987; Louis, 1980). For example, Wilson (1986) and Darling (1986) call for the study of communication strategies by which individuals reduce uncertainty and acquire information needed to take on organizational roles. Yet, as Jablin (1984) observed, "most organizational assimilation research has focused on the process from the organization's perspective" (p. 596). Research examining the individual's perspective is needed.

Second, scholars have often adopted stage models in order to conceptualize the socialization process as it takes place over time (Feldman, 1976; Schein, 1971; Van Maanen, 1975). Models incorporate from three (Van Maanen, 1975) to six (Wilson, 1984) stages through which the organizational socialization process moves. Researchers typically assume that these stages transform individuals from "outsiders" into functioning "insiders" or members. In general, newcomers arrive with sets of expectations, experience a great deal of uncertainty, learn how things are done, how to adopt the appropriate organizational roles, and which of their expectations are inaccurate. Eventually, they adapt themselves in order to perform their organizational roles. Although there is collectively some uncertainty regarding specific time frames, researchers have conducted studies purporting to measure specific socialization phases (Brown, 1985; Darling, 1986; Jablin, 1984). These models are helpful in understanding change as a broad general phenomenon. They do not describe specific points of change.

The third approach addresses outcomes. Eventually, some newcomers become members. They become committed to, integrated into, or identified with the organization (Buchanan, 1974; Feldman, 1976; Jablin, 1986; Van Maanan, 1976; Wilson, 1984). Organizational identification is frequently included in models of socialization (Jablin, 1986; Kleinman, 1983). 


\section{IDENTIFICATION AND SOCIALIZATION}

As Tompkins et al. (1975) originally noted, identification is one of several key terms in Kenneth Burke's grand theory of the social order. Burke uses the terms hierarchy, order, mystery, and identification to describe the workings of the social order. He views the formal organization as a special case within the broader social order. While hierarchy, order and mystery are associated with the underlying tendency toward segregation (Burke, 1973), identification is associated with the related tension in Burke's dialectic, the underlying tendency toward congregation. As Burke (1950, p. 115) argues, "in mystery there must be strangeness; but the estranged must also be thought of as in some way capable of communion." In Burke's scheme, identification is a fundamental associational dimension along which change takes place as individuals strive to overcome division, or mystery (Cheney, 1983b).

Identification is both a process and a product (Cheney \& Tompkins, 1987). While it is often treated as an outcome of socialization (Jablin, 1986), we also conceptualize it as an ongoing process related to the mystery and division inherent in organization. From his thorough review of the literature, Cheney (1982) concludes that individuals experience organizational identification as feelings of similarity, belonging, and membership. Individuals identify with collectives (in this case, graduate departments) to the extent that they feel similar to other members, they feel a sense of belonging, and they consider themselves to be members. The extent to which individuals identify with various targets may change over time. Therefore, while identification may be treated as an outcome or product, researchers should remember that individuals' perceptions and feelings of identification may be expected to change over time. Identification, then, as a fundamental process of relational development and as a product involving feelings of similarity, belonging, and membership, is integrally related to the socialization process. These conceptualizations would lead one to predict that identification would increase in those newcomers who are successfully "transformed" into members during socialization. This relationship is explicit in many discussions of socialization (Jablin, 1986; Kleinman, 1983).

Much research (reviewed in Tompkins \& Cheney, 1985) follows Cheney $(1983 \mathrm{~b})$ in emphasizing the active role played by organizations in generating identification within individual members. Although identification is conceptualized as an active process individuals engage in, it is typically not treated as such. Instead, organizational messages and practices are assumed to create identifications.

\section{PURPOSE}

The socialization literature has slighted participants' perceptions of their socialization experiences. Identification research has also focused on organizational strategies more than individual experiences. Yet, both 
socialization and identification are processes in which individuals necessarily participate. Darling (1986) points out that research which is based on the assumption that individual intent and meanings are important needs to incorporate methods which are consistent with this assumption. Similarly, Cheney (1987a) emphasizes the need for researchers to understand the constraints which are self-imposed by the terms employed and relationships among terms which are implied. He advises researchers to listen to how contributors to organizations talk about their relationships with the organizations.

The purpose of this research is to examine participants' accounts of change in the individual-organizational socialization relationship. We assume that: (1) Socialization is a process, (2) Identification is a fundamental dimension along which change occurs (Burke, 1973), (3) Participants' accounts of change need to be examined in order to understand their experiences, and (4) The method employed needs to be consistent with the goal of listening to participants as they define their change experiences.

\section{TURNING POINT ANALYSIS}

We adopt turning point analysis as a method for answering these concerns. Bolton (1961) first used the term to discuss patterns of change. Baxter and Bullis (1986) defined a turning point as "any event or occurrence that is associated with change in a relationship," (p. 470) and argued that turning points constitute "the substance of change" (p. 470). Several researchers have used turning point analysis in the study of change in developing romantic relationships to examine rates of change in relationship progress (Huston, Surra, Fitzgerald \& Cate, 1981), reasons given for relational changes (Lloyd \& Cate, 1984; Surra, 1984), and stages of relational development (Braiker \& Kelly, 1979). Baxter and Bullis (1986) used the turning point as a unit of analysis upon which to base a descriptive profile of change in the processes of relational development. After discovering that partners were able to describe a variety of events (including both internal and interaction-based, both specific and general), they concluded that the turning point "potentially affords a rich understanding of relationship processes" and "has been underutilized to date by researchers" (Baxter \& Bullis, 1986, pp. 470-471).

The turning point is a valuable unit of analysis in organizational socialization research, because turning point analysis: (1) does not assume that the socialization process follows a clear pattern of growth as do phase models and identification research, (2) allows a detailed examination of change points identified by participants rather than relying on researcher-generated definitions, (3) collects self reports in such a way that participants need not rely on their memories of events which occurred in the distant past, and (4) relies entirely on the reports of individuals who are actively involved in socialization processes to report their experiences rather than relying on the organization's perspective. 


\section{RESEARCH QUESTIONS}

We posed five research questions:

RQ1: What phenomena comprise socialization turning points in the perceptions of organizational newcomers?

RQ2: Do specific turning point events coincide with specific socialization phases?

RQ3: Do types of turning points differ in the degree to which they affect participants' experiences of immediate change in organizational identification?

RQ4: Is organizational identification (as outcome) associated with the presence or absence of specific types of turning points?

RQ5: Does organizational identification (as outcome) increase over time?

\section{METHODS}

\section{Participants}

Participants were 28 entering graduate students enrolled in master's or doctoral degree programs in three communication departments. All students who entered the three departments were contacted during the first week of class, asked to participate in the study throughout the academic year, and agreed. Graduate students were used for two reasons. First, they typically enter an organization in numbers. Thus, one may observe the development of an individual-organization relationship from the perspective of several newcomers within the same organization. Wanous (1980) asserts that it is much easier to observe how individuals "personalize" their socialization when they enter an organization in a group rather than individually. Second, the methods employed in this study have been previously developed and successfully employed with student populations.

Some studies of graduate department socialization focus on the departments as agents of professional role training (c.f. Pavalko \& Holley, 1974; Rosen \& Bates, 1967; Weiss, 1981). These studies analyze the degree to which students gain professional role identities and emphasize the unique role of graduate departments. Other studies emphasize similarities between graduate departments and other organizations. For example, Tompkins and Cheney (1985) studied organizational identification in a graduate department, and Darling $(1986,1988)$ studied graduate students in her investigation of organizational socialization. In this research, we adopt the latter view.

Initially 29 students agreed to participate. Due to participant mortality during the academic year, complete data were collected for 28 students. Approximately two-thirds (65\%) of our sample were women. Twenty-three (82\%) were enrolled in a master's program and five $(18 \%)$ were doctoral students. The mean age of the participants was 33.1 years.

\section{Measures}

The Retrospective Interview Technique (RIT) was used to acquire turning point data. This technique has been employed successfully in the study of romantic relationship turning points (Baxter \& Bullis, 1986; 
Huston, et al., 1981; Lloyd, 1983; Lloyd \& Cate, 1984). Miell (1984) argued for the validity of the technique after finding that people were highly accurate in recalling turning points. In another study, Stohl (1986) found that an overwhelming percentage of respondents were able to recall a specific message which had a lasting influence on their life.

Researchers using the RIT ask individuals to identify and plot all the turning points in their relationships since first meeting their relational partners. Participants typically plot points on graphs with the abscissas representing time in months from first meeting to the time of the interview and the ordinates representing an index of relationship commitment. As each point is plotted, interviewers probe for additional information about the point. The graphs provide a tool through which interviewees are able to envision their relationship over time. Since they take on the role of filling in the graphs, they typically become quite actively involved in creating a final graph which is the best possible representation of their relationships. The accounts may not be identical to those which would result from participants monitoring turning point experiences as they occur, but they should reflect those experiences which occurred during a reasonable period of time preceding the interviews.

The RIT used in the present study was adapted to explore the individual-organization relationship. Two interviews were conducted with each participant, the first approximately 4 months after the beginning of the academic year (or two weeks into the second quarter) and the second approximately 4 months after the first, or 3 weeks prior to the end of the academic year. In discussing socialization stages as they relate to graduate students, we follow Darling (1986) in her assumption that the first quarter may meaningfully be construed as an entry stage. We assume that the second and third quarters may meaningfully be construed as later stages. Newcomers have gained the experience of one meaningful unit. They have met people, experienced one cycle (written papers, taken tests, registered, managed schedules, etc.), and begun further cycles. The four month intervals were also helpful in avoiding two extremes which have plagued previous research. In order to understand long term developmental processes from participants' perspectives, researchers frequently rely on interviews which require participants to describe change which occurred over many years (e.g. Kram, 1985). In these studies, results are suspect due to reliance on long term recall (Kram, 1985). At the other extreme is the tendency toward one-shot studies which suffer from adopting static models of relationships among variables (Jablin, 1984). By employing the RIT at four month intervals, we were able to avoid these pitfalls. Both interviews were identical and focused on turning points which occurred during the four months preceding the interview. Participants were introduced to the purpose of the study, the definitions of turning points and of identification, and were provided with assurances of confidentiality. Graphs indicating monthly intervals on the ordinates and level of identification with the department on the abscissas, were then provided (Figure 1). 


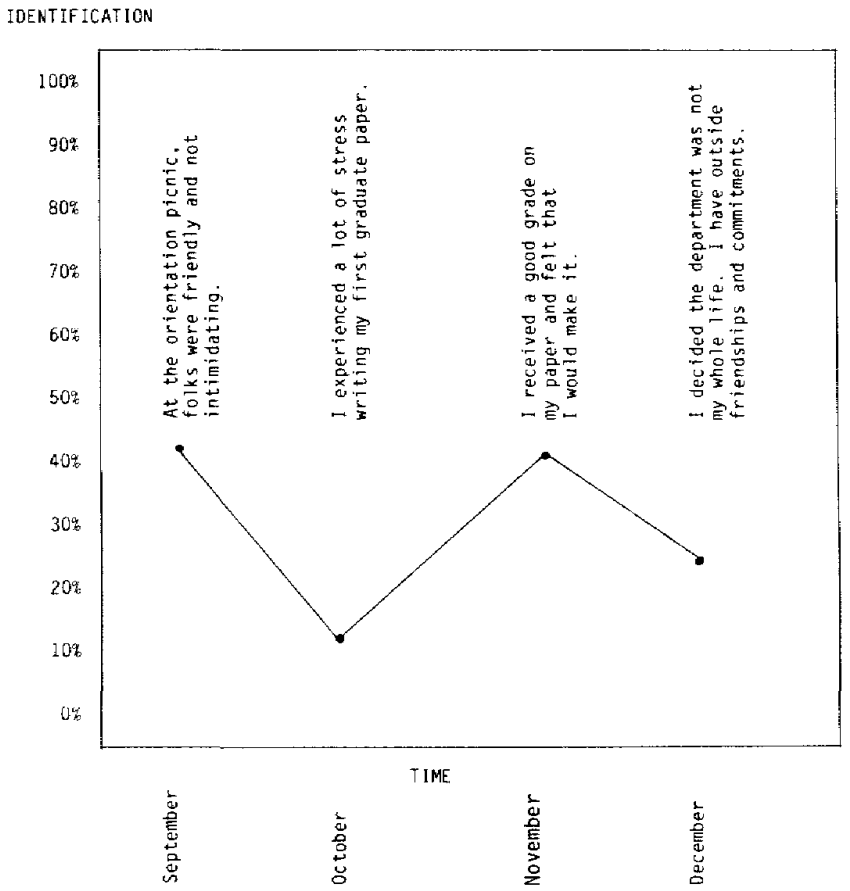

Figure 1. RIT GRAPH

Participants first plotted and explained their identification levels at the time of the interviews and at the beginning of the preceding fourmonth period in order to provide anchor points by which to judge the intervening changes. They then plotted points in between when identification increased or decreased. As each point was identified and plotted, interviewers probed for details regarding the change in identification. Finally, the participants drew lines to indicate the nature of connections between the turning points and the points which immediately preceded. This procedure continued until all relevant points were identified. Participants were then instructed to look back over the entire graph and make any changes they considered appropriate. 
Level of identification with the academic department was assessed with a shortened version of the Organizational Identification Questionnaire developed by Cheney (1983a). The twenty-five item OIQ has been used in a number of organizational studies (Bullis, 1984; Cheney, 1983a; Cox, 1983; Dionisopoulos \& Samter, 1983) and was initially tested on a sample of communication graduate students which represented a population similar to that used in the present study. Internal reliability has been consistently reported to be .94 using Cronbach's alpha (Bullis, 1984; Cheney, 1983a). The alpha coefficient for the seventeenitem version was .90 . The OIQ was completed by participants during the second week of the academic year and again after eight months. Change in outcome identification was derived by subtracting the second score from the first.

\section{PROCEDURES}

Interview notes were condensed into concise descriptions of turning point events. We then inductively derived a set of 15 turning point types. Working independently, each researcher generated a set of turning point categories using the "clustering" technique described by Miles and Huberman (1984). Categories were then compared and collapsed into a single set. Both researchers independently coded all turning points into the categories. This resulted in an absolute agreement of .86 . Reliability was computed using Cohen's (1960) kappa and found to be .85 .

The OIQ scores were derived by summing the scores of the seventeen 7-point Likert Style questions and dividing the sum by seventeen.

Following Baxter and Bullis (1986), change in immediate identification was derived directly from participant graphs by subtracting the identification level at each turning point from the level indicated on the graph immediately preceding the change. This difference was then divided by the time (in months) over which the change occurred. Those points with an identification difference score greater than zero were positive turning points while those points with an identification difference score less than zero were negative turning points.

\section{RESULTS}

\section{Question 1}

The first research question asked for the identification of types of turning points experienced by individuals during the organizational socialization process. A total of 283 turning points were identified. Respondents reported a mean of 12.3 turning point events per account, while the number of turning points ranged from 4 to 18 per respondent. The turning point types with their respective frequencies and changes in identification levels are summarized in Table 1. 
TABLE 1

Turning Point Categories and Levels of Change

\begin{tabular}{lrrr}
\hline & & & $\begin{array}{c}\text { Mean Change in } \\
\text { Identification } \\
\text { by Month }\end{array}$ \\
\hline Moving In & Frequency & $\%$ & $(1.4$ \\
Settling In & 4 & 7.1 & 10.44 \\
Socializing & 20 & 8.1 & 56.49 \\
Sense of Community & 23 & 17.7 & 29.16 \\
Receiving Informal Recognition & 50 & 7.4 & 114.82 \\
Gaining Formal Recognition & 21 & 7.1 & 51.58 \\
Jumping Informal Hurdle & 20 & 6.7 & 24.76 \\
Approaching Formal Hurdle & 19 & 12.0 & 28.41 \\
Representing the Organization & 34 & 3.9 & 50.89 \\
Disappointment & 11 & 7.4 & -21.24 \\
Protecting One's "Self" & 21 & 2.8 & ( \\
Doubting One's "Self" & 8 & 5.3 & -15.25 \\
Getting Away & 15 & 5.3 & -88.08 \\
Alienation & 15 & 5.7 & -78.96 \\
Miscellaneous & 16 & 2.1 & ( \\
& 6 & & \\
\hline & 283 & & \\
\hline
\end{tabular}

A. Moving In. Moving In refers to the establishment of a physical territory or space within the organization as well as becoming familiar with the surroundings in which the organization exists. Receiving the key to one's office, having a departmental mailbox or one's name on an office door all contributed to the establishment of a sense of place. Ownership of the environment or objects in the environment also characterized Moving In. One respondent claimed that, " Hall is my department, my building," while another respondent noted that, "I chose my desk, which was important. . . my 'space' where I would be the next two years." Increased familiarity with the campus was also a factor in the establishment of "place" and an increase in identification.

B. Settling In. The process of Settling In occurred as one established a routine and became comfortable in the role of graduate student. During the Settling In process one typically became aware of organizational expectations. Claims such as, "I had handled the role confusion. I was secure in my role," "I'm learning how you get along and what's going on," and "intellectually, I'm finding my niche" were typical of comments which reflected this process.

C. Socializing. Socializing involved informal discourse with graduate students or faculty outside the classroom. Socializing events were either 
spontaneous or endorsed by a department for the primary purpose of informal communication. Spontaneous events were typically "pub runs," to a local tavern or sharing jokes, stories, gossip, and the like with professors and peers outside of class and in the privacy of one's office or "place." Departmentally-endorsed events included orientation picnics, a departmental Halloween party, a departmental progressive dinner, and a departmental softball game. Socializing promoted familiarity with other graduate students and faculty and provided an outlet for graduate students to talk about themselves, their interests, and their professors.

D. Sense of Community. This turning point refers to an overall sense of identification with the department. Sense of Community was experienced as a cognitive or emotional state of organizational identification. Cognitive expressions of community were a product of individual perception-a "meshing" of self and organizational identities. Typical of the responses in this category were those that asserted, "School is who I am," or "I am a scholar and we are a community of scholars." One student captured the essence of community by stating, "What you spend time doing you begin to identify yourself with!"

An emotional Sense of Community was brought upon by the act of including oneself as well as being involved in the day-to-day interactions which led to this inclusion. Reports commonly described the giving and receiving of social support, feeling connected to others in the department, and spending increased amounts of time in the department. One new student reflected a feeling of inclusion during orientation week by stating that "during a conversation, Sue (a veteran) said 'we' instead of 'you' or 'I.' I felt like part of it all."

E. Receiving Informal Recognition. Any report of receiving positive feedback was coded as Receiving Informal Recognition. Recognition came from other peers or professors and was comprised of general, informal, positive comments. Receiving Informal Recognition from peers typically involved positive feedback about one's work. Recognition from a professor included positive feedback or feeling treated as an equal. Several respondents noted that "profs treat me as an equal rather than an undergrad," or "faculty treat us like people," or are "responsive to our concerns." Receiving Informal Recognition brought about the greatest positive change in identification and was reported more frequently during conversations with professors than with other students.

F. Gaining Formal Recognition. In contrast to Receiving Informal Recognition, Gaining Formal Recognition consisted of receiving awards bestowed by the organization or receiving positive feedback for successfully completing organizational tasks. Gaining Formal Recognition involved the award of a scholarship, a grant, or teaching assistantship. The good grade received on a class assignment or the acceptance of a convention paper were alșo considered Gaining Formal Recognition. Finally, being asked to work for or with a professor on a project was a sign of Gaining Formal Recognition. 
G. Jumping Informal Hurdles. Jumping Informal Hurdles resulted in a positive change in identification. Hurdles were perceived as internal roadblocks to the respondent's success as a graduate student. "Winning" or "overcoming" these hurdles generally resulted in a sense of victory or a feeling that one would "make it despite the odds." One respondent explained "I felt like I had conquered a part of myself. I realized that I CAN do this [graduate school]. I am as strong as I need to be and I came through when I needed to," or "I saw the light at the end of the tunnel and felt a gradual improvement in my work."

H. Approaching Formal Hurdles. Unlike the Informal Hurdles, Formal Hurdles promoted either positive or negative identification. Formal Hurdles were described as "hoops" through which the student must jump to complete a graduate education. Formal Hurdles with positive outcomes included the selection of one's chair and committee, the successful completion of class requirements and the successful completion of the first quarter (as determined by the student's G.P.A.). A respondent's identification would decrease when the Formal Hurdle entailed some difficulty or was not successfully completed. One student described his decrease in identification with the comment, "Writing the paper for this class was a time of heavy stress. The enormity of the assignment overwhelmed me. It told me I wasn't prepared."

I. Representing the Organization. Respondents often interacted in other campus departments or outside the academic community. A student expressed his establishment of a boundary role: "Taking a political science class made me feel good about being in communication. We had to do a group presentation and I was the leader for it-I did the introduction, the transitions, etc. I was the 'comm guy.' I could use all of my comm[unication] skills-people thought I was great without realizing why. It was my comm[unication] skills." Representing The Organization was also evident when the respondent was a teaching assistant, representing the department to undergraduates.

J. Disappointment. Disappointment occurred when the organization or its members were less "perfect" than originally perceived. Examples of Disappointment included frustration with the content or teaching methods of a particular class. As one student reported, "The communication variables in this particular class weren't being met. At this time I began to think that the situation was not as rosy as I thought. I was getting really disgruntled with the course." Disappointment with professors typically involved a disagreement or conflict with a professor's behavior or research philosophy. The most common Disappointment, however, occurred when "the department" did not meet the student's expectations. The statement "I was the darling of my former department and had a lot of attention and feedback. Here it's zip. The faculty doesn't care," was typical of the sentiments expressed by several respondents. Another interviewee stated, "I don't buy into the philosophy of this department-the course requirements and emphasis on papers at conventions." 
K. Protecting One's "Self." Protecting One's "Self" involved behaviors enacted by respondents to avoid being "consumed" or "swallowed" by their involvement. The act of self protection was internal and was not triggered by a specific target.

In other words, Protecting One's "Self" entailed a conscious move to disassociate so that one would not feel overburdened by departmental requirements or social contacts. Although there were only eight reports of Protecting One's "Self," they could be summed by one woman who said, "School is not my life. I'm not entrenched in the field or the department."

L. Getting Away. Getting Away was associated with the greatest decrease in organizational identification. Getting Away involved the association with a specific target external to the department. As respondents "got away," less physical and emotional time was spent in department-related activities. Getting Away included increased involvement with family, attending classes outside the department, and the development of personal relationships external to the department. Several respondents voiced the desire to "get away" from their respective departments to see if life existed outside.

M. Alienation. Alienation is the opposite of a sense of community and defined as a perceived lack of community or an internal feeling of difference between self and other in the department. Alienation always produced a loss of organizational identification. As one person reported, "I had no history that everyone else felt. I felt a sense of difference-an event that was significant to others was insignificant to me." Another person noted, "I didn't feel as if I fit in with the ages or the conversation. There were many people my age but they seemed more sophisticated."

N. Doubting One's "Self." Respondents who reported Doubting One's "Self" reported experiences which led them to question their competence as well as their ability to make a valuable contribution to the department. One person responded, "My loss of ID came from my questioning, 'I don't know if I can cut it in grad[uate] school!" " A second person stated, "I was doubting my competence and whether I was able to be a grad. My self-esteem was really down; I was doubting my sanity and was wondering if I had made the right choice to come here."

O. Miscellaneous. Turning points which did not fit into any of the above categories were coded as miscellaneous. Only six cases were included into this category.

\section{Question 2}

The second research question asked whether specific types of turning points are associated with specific socialization phases. The total number of reported turning points differed across phases. Sixty-three percent occurred during the first-time period, and $37 \%$ occurred during 
the second time period $\left(\chi^{2}=8.76, d f=1, p<.005\right)$. Chi square computations compared occurrences of each of 13 turning-point types between the first and second turning point interviews (two turning-point types, Moving In and Miscellaneous, were not analyzed due to low $n$ 's). Expected frequencies for each type were based on total proportions of turning points which occurred during the respective time periods.

Results indicate that the vast majority of types did not differ significantly in frequency of occurrence during the two different time periods. One type, Socializing, occurred significantly more often during the first time period $\left(\chi^{2}=4.15, d f=1, p<.05\right)$. Another type, Formal Recognition, occurred more frequently than expected during the second time period $\left(\chi^{2}=10.97, d f=1, p<.005\right)$.

\section{Question 3}

The third research question was asked to determine whether different types of turning points were associated with different amounts of immediate change in identification. The mean immediate change in identification for each type is included in Table 1. A one way ANOVA was computed which included turning point types with frequencies greater than 10 ( 3 categories were excluded). The ANOVA results suggest that the different types of turning points did differ significantly in their impact on immediate identification $(F=7.05, d f=11 ; p<.002)$. The Student Newmann-Kuels computations revealed two differences. First, Getting Away, and Alienation, which produced the two largest immediate drops in identification, were significantly different from the turning points which led to positive changes in identification (e.g., Settling In, Socializing, Sense of Community, Gaining Informal Recognition, Formal Recognition, Jumping Informal Hurdles, Approaching Formal Hurdles, Representing the Organization). Second, Receiving Informal Recognition was significantly different from all other turning points except Gaining Formal Recognition and Representing the Organization.

\section{Question 4}

The fourth research question explored the extent to which the outcome level of organizational identification after eight months was associated with the presence or absence of specific turning point types. A series of $t$-tests compared identification levels between participant accounts in which a given turning-point type was present with those in which the same turning-point type was absent.

OIQ scores differed significantly based on the presence or absence of two turning-point types. Participants who reported Socializing on at least one occasion reported higher levels of outcome identification than did participants whose accounts did not include any instances of Socializing $(t=2.07, d f=22.30, p<.05)$. Participants who reported at least one instance of Disappointment reported lower outcome identification than did participants who did not $(t=2.72, d f=15.78, p<.015)$. 


\section{Question 5}

The difference between second week OIQ scores and those after eight months was examined in order to determine whether organizational identification increased. The mean difference score was -0.242 . The median score was -0.176 . The difference scores ranged from -2.47 to 1.06 . Ten difference scores were positive, reflecting increases. Eighteen difference scores were negative, reflecting decreases. The mean decrease in identification over the eight month period was not statistically significant.

\section{DISCUSSION}

This study identified turning points which new graduate students in three communication departments reported during their first academic year. Implications were derived by listening to participants' comments and examining them in the context of relevant theory.

The array of turning point types identified includes many which extend beyond the search for role-taking information. None emphasizes overt information gathering about norms, values, or the way things are done. However, Moving In and Settling In aid newcomers in their roletaking experiences. Socializing may well function as an opportunity for learning values and norms.

Several turning point types (Receiving Informal Recognition, Gaining Formal Recognition, Jumping Internal Hurdles, Approaching Formal Hurdles, and Doubting One's "Self") underscore the importance of evaluative information (Lester, 1986; Wilson, 1986). For example, Receiving Informal Recognition produced the greatest immediate change in organizational identification and was significantly different in this regard from most other turning point categories. These newcomers were most likely to experience immediate increases in identification when they received unsolicited recognition. Lyman and Scott (1970) suggest that "stage-fright" occurs when newcomers experience apprehension about their competence. Unsolicited positive feedback greatly relieves newcomers' uncertainty. Lester (1986) discusses two domains of uncertainty, evaluative and behavioral. In this study, positive reduction of evaluative uncertainty appeared to be more salient. These accounts emphasized the importance of positive relational information. Although quantitatively more interaction may center around task information (Brown, 1985), these participants suggest that qualitatively positive relational feedback is far more important to identification. These reports and the associated strong positive change in immediate identification may suggest that a kind of organizational confirmation is a critical turning point in the development of the organizational relationship. This confirmation may be as important in the newcomer's relationship with the organization as interpersonal confirmation is theorized to be in dyadic relationships (Buber, 1957; Cissna, 1976; Jablin, 1979; Watzlawick, Beavin \& Jackson, 1967). Confirming responses acknowledge the agency 
of the human being. Interpersonal confirmation has been labeled the basic dimension (Cissna \& Sieburg, 1979) of human communication. Graduate students may have little interaction with the faculty (Darling, 1986), making confirmation difficult to obtain.

These participant accounts reinforce the call of researchers for multiple levels of analysis (Cheney, 1987b; Jablin \& Krone, 1987; Wilson, $1986)$ in the study of socialization. Some turning point types are centered in intra-individual experiences such as doubts or victories (Jumping Internal Hurdles, Doubting One's "Self," Sense of Community, and Alienation). Others depend on interactions with specific organizational members (Receiving Informal Recognition), while still others depend on the organization itself (Gaining Formal Recognition). Representing the Organization underscores the salience of messages from the organizational environment to the socialization of members.

Many of these turning point types indicate that newcomers are actively involved in perceiving, evaluating, and managing their relationships with their respective organizations. They present an obvious divergence from the anthropological conception of primary socialization and support the distinction between primary and secondary socialization. Moreover, these newcomers were more likely to experience a decrease rather than an increase in identification over time. This result calls into question the view of socialization as a process in which newcomers are transformed into members. Newcomers may stay but not become identified with the organization. Specific experiences such as those described as Disappointment may lead to lower identification, and "unsuccessful" socialization. This outcome may be as common as "successful" socialization or even more common. If it is, issues arise regarding the "successful" outcomes of socialization, the desirability of such outcomes, and the practice of managing experiences of newcomers.

These accounts offer some solace to scholars who are concerned abcut the control of organizations over their members. Newcomers reported actively protecting themselves from complete inclusion, and they also reported valuing Socializing and Settling In. They reported purposively Getting Away as well as Jumping Hurdles toward the organization. They reported experiences of Alienation and experiences of Community. More than half reported decreases in identification during their first year. This pattern is more consistent with Burke's dialectic than with organizational control. Newcomers described actively striving toward both identification and division.

Given the power of the terms we employ to guide our possibilities, our vocabulary for individual-organizational relationships needs to be carefully scrutinized. The term "assimilation" (Jablin, 1982) embraces both "socialization" and "individualization." This term assumes that newcomers create and define their roles within the organization. We need to continue to seek terms that expand the individual's potential impact on the organization itself. Current terms encourage us to reify the power 
of the organization at the expense of the individual. We need terms which emphasize individuals as agents, adults rather than infants, engaging in coordinated action (Barnard, 1938). For example, Wilson (1984) recommended thinking of individual-organizational relationships like interpersonal relationships in order to emphasize that participants determine the fate of the relationship rather than determining only their own individual roles within it.

The results of this study also caution those who would adopt the assumptions of phase models of socialization. On the one hand, the frequency of reported turning points was higher during the first four months (or first academic quarter) than the second four month period. This is consistent with socialization models which assume that uncertainty is high during the early relationship which leads newcomers to attend more to all events. The high level of Socializing during the first time period is also consistent with past research (Jablin \& Krone, 1987). The higher occurrence of Formal Recognition during the second time period suggests that this is an important memorable event. It also reflects temporal structure. The formal awards are simply not (typically) available earlier.

On the other hand, the more interesting result is the lack of pattern evident in the other eleven turning point types. Phase models would predict more consistency within time frames and less consistency between time frames. These reports indicate that the types of meaningful events which occur across time often may not respect developmental models. The occurrence of the negative turning point types early in the course of the relationship illustrates this. Stage models assume that the early period of relational development is a time of growth. Later, as the relationship decays, decline predominates. These participants, however, articulated Getting Away and Alienation during the first academic year. These turning point types were significantly different from all others in the degree to which they were associated with immediate decreases in identification. In Getting Away, the individuals were actively in volved in disassociating themselves from the organization. Identifications were redirected from the organization to different targets. Some of these events had to do with external targets which participants had de-emphasized for a period of time. Others occurred as a result of participants' active needs to get away from their intense involvements with their departments. Alienation was brought about by a perceived mismatch (Wanous, 1980) or lack of "fit" (Wilson, 1984) between the individual and the organization. If a newcomer perceived a difference between self and others, identification decreased. Perceived mismatches typically manifested themselves as newcomers heard or observed organizational values, goals, collective experiences, etc.

Moreover, participants involved in these relationships did not experience a gradual growth in the relationship during the first eight months as phase models suggest, but rather a wider range of ups and 
downs. These results are consistent with Baxter's (1988) recent reconceptualization of interpersonal relational development. In her critique of change phases, she posits change nodes which occur throughout the relationship as participants continually manage a variety of dialectic tensions. Similarly, these participants' descriptions of turning points describe an ongoing tension between movement toward identification, congregation, and the communion of similar beings on the one pole (Socializing, Sense of Community, Formal Recognition, Approaching Formal Hurdles, Representing the Organization) and movement toward division, mystery, and the segregation of estranged beings on the other (c.f. Doubting One's "Self," Getting Away, Alienation).

Although caution regarding phase models is warranted, the broad conceptualization of change they offer should not be supplanted by one which ignores broader patterns. Rather, comprehensive models which incorporate both are needed. Those events reported to have the greatest immediate impact on identification (Informal Recognition, Getting Away, and Alienation) are different from the events associated with level of identification as measured after eight months (Socializing and Disappointment). Researchers cannot assume that a detailed, fine-grained examination of change (such as turning points) yields a more specific description than that depicted in broader stage models. Events which are experienced as strong turning points may recede in their importance over time while others have stronger longer term effects. For example, Receiving Informal Recognition produced the greatest positive immediate change in identification but was not associated with higher longer term identification.

In contrast, newcomers who reported Socializing on at least one occasion reported higher levels of identification after eight months than did participants who did not. Yet they did not identify Socializing events as those which created the highest immediate changes in identification. These results are consistent with previous research which found that newcomers typically emphasize social relationships (Feldman \& Brett, 1983; Katz, 1980). Socializing may serve as a means of holistic inclusion (Ouchi, 1981), directly enhancing the degree to which participants' identities merge with the organization.

Similarly, newcomers who reported at least one instance of Disappointment reported lower levels of identification after eight months than those who did not. Newcomers may assume a certain level of identification (Simon, 1976) based on inflated, unrealistic expectations (Jablin, 1986; Wanous, 1980). Unmet expectations then function as catalysts for decreases in identification. Disappointment appears to create a decrease in identification from which the relationship does not recover.

These results do not support the contention that time leads to stronger identification as newcomers are transformed to insiders. More OIQ scores decreased than increased. The detailed analysis used here helped to explain this pattern of change in outcome identification. 
Turning point analysis using the RIT appears to be a viable method for examining a variety of issues associated with change in the individual-organization relationship. It was used here to listen to participants recall salient events over time. It proved to be more valuable than we had anticipated. We assumed that turning points were specific events which occur at specific temporal moments. These participants articulated internal experiences and general periods of change in evolving patterns of behavior unmarked by specific memorable events. The method did not preclude participants from telling their experiences when their experiences did not fit with our expectations.

Researchers may address a host of specific questions through turning point analysis. For example, further research should investigate the generalizability of these findings. Future research should also extend over a longer time period, identify pre-entry turning points, and identify common trajectories of sequential turning points. There should be more continuous monitoring of participants to gather accounts of the time turning points occur. The roles of holistic inclusion, organizational confirmation, relational level uncertainty, and realistic expectations in the development of organizational identification posited here need to be explored. Clusters of specific types of turning points may be indicators of unique cultures or subcultures.

Research needs to incorporate organizational and individual perspectives and contextual constraints. Individual experiences should be examined for their associations with various organizational socialization practices and outcomes. The issue of individual agency should be probed.

These findings call for further examination of the identificationdivision tension identified here. Strategies members and "organizations" (supervisors, policies, practices) use in managing this tension, communicative situations in which it surfaces, and effects of strategies over time should be probed. Models of change which incorporate both immediate change and long-term change are needed.

\section{ENDNOTE}

1. This research was supported by a grant from the University of Utah. The authors express appreciation to Kim Wells for her help with data collection.

Portions of this paper were presented at the annual meeting of the Speech Communication Association, Chicago, 1986, and at the annua] meeting of the Western Speech Communication Association, Spokane, 1989.

\section{REFERENCES}

Barnard, C. (1938). The functions of the executive Cambridge, MA: Harvard University Press.

Baxter, L. (1988). Dialectical perspective on communication strategies in relational development. In S. Duck (Ed.) Handbook of Personal Relationships: Theory, research, and interventions (pp. 257-273). New York: John Wiley \& Sons.

Baxter, L. \& Bullis, C. (1986). Turning points in developing romantic relationships. Human Communication Research, 12, 469-493. 
Bolton, C. D. (1961). Mate selection as the development of a relationship. Marriage and Family Living, 23, 234-240.

Braiker, H. B., \& Kelley, H. H. (1979). Conflict in the development of close relationships. In R. L. Burgess and T. L. Huston (Eds.), Social exchange in developing relationships (pp. 135-168). New York: Academic Press.

Brim, O. G., Jr. (1966). Socialization through the life cycle. In O. G. Brim, Jr. and S. Wheeler (Eds.), Socialization after childhood: Two essays (pp. 1-49). New York: John Wiley \& Sons.

Brown, M. H. (1985). That reminds of a story: Speech action in organizational socialization. Western Journal of Speech Communication, 49, 27-42.

Buber, M. (1957). Distance and relation. Psychiatry, 20, 97-104.

Buchanan, B. (1974). Building organizational commitment: The socialization of managers in work organization. Administrative Science Quarterly, 19, 533-546.

Bullis, C. (1984). The forest ranger revisited. Unpublished doctoral dissertation, Purdue University.

Burke, K. (1950). A rhetoric of motives. NY: Prentice Hall.

Burke, K. (1973). The rhetorical situation. In L. Thayer (ed.), Communication: Ethical and moral issues (pp. 263-275). NY: Gordon and Breach.

Cheney, G. (1982). Organizational identification as process and product: A field study. Unpublished master's thesis, Purdue University.

Cheney, G. (1983a). On the various and changing meanings of orgenizational membership: A field study of organizational identifieation. Communication Monographs, $50,342-362$.

Cheney, G. (1983b). The rhetoric of identification and the study of organizational communication. Quarterly Journal of Speech, 69, 143-158.

Cheney, G. (1987a, November). On identity, organization, and transcending levels of analysis in communication research. Paper presented at the meeting of the Speech Communication Association, Boston.

Cheney, G. (1987b, November). A rhetorical-critical look at the processes of organizational socialization. Paper presented at the meeting of the Speech Communication Association, Boston.

Cheney, G. \& Tompkins, P. K. (1987). Coming to terms with organizational identification and commitment. Central States Speech Journal 38, 1-15.

Cissna, K. (1976). Interpersonal confirmation: A review of current theory, measurement, and research. Saint Louis: Saint Louis University (ERIC Document Reproduction Service No. Ed 126 544).

Cissna, K., \& Seiburg, E. (1979). Interactional foundations of interpersonal confirmation. Paper presented at the International Communication Association and Speech Communication Association Postdoctoral Conference, "Human Communication from the Interactional View," Asilomar, California.

Cohen, J. (1960). A coefficient of agreement for nominal scales. Educational and Psychological Measurement, 20, 37-46.

Cox, M. (1983). The effectiveness of Black identification and organizational identification on communication supportiveness. Unpublished doctoral dissertation, Purdue University.

Darling, A. L. (1986, November). On becoming a graduate student: An examination of communication in the socialization process. Paper presented at the meeting of the Speech Communication Association, Chicago.

Darling, A. L. (1988, November). Graduate student socialization. Categories of encounters. Paper presented at the annual meeting of the International Communication Association, New Orleans.

Dionisopolous, G., \& Samter, W. (1983). Identification by antithesis: An analysis of the "us versus them" orientation by police. Paper presented at the meeting of the Eastern Communication Association, Ocean City, MD.

Falcione, R. L., \& Wilson, C. E. (1988). Socialization processes in organizations. In Goldhaber, G. and Barnett, G. (Eds.), Handbook of organizational communication. New York: Ablex. 
Feldman, D. C. (1976). A contingency theory of socialization. Administrative Science Quarterly, 21, 433-452.

Feldman, D. C. (1988). Managing careers in arganizations. Glenview, IL: Scott Foresman \& Company.

Feldman, D. C., and Brett, J. M. (1983). Coping with new jobs: A comparative study of new hires and job changers. Academy of Management Journal, 26, 258-272.

Huston, T. L., Surra, C., Fitzgerald, N. M., \& Cate, R. (1981). From courtship to marriage: Mate selection as an interpersonal process. In S. Duck and R. Gilmour (Eds.), Personal relationships 2: Developing personal relationships (pp. 53.88). London and New York: Academic Press.

Jablin, F. (1979). Superior-subordinate communication: The state of the art. Psychological Bulletin, 86, 1201-1222.

Jablin, F. (1982). Organizational communication: An assimilation approach. In M. E. Roloff \& C. R. Berger (Eds.), Social cognition and communication (pp. 255-286). Beverly Hills, CA: Sage.

Jablin, F. (1984). Assimilating new members into organizations. In R. Bostrom (Ed.), Communication Yearbook, 8 (pp. 594-626). Beverly Hills, CA: Sage.

Jablin, F. (1986, May). What is organizational assimilation? An overview of communication, socialization and individualization processes. In L. Putnam (Chair), Communication and organizational socialization. Preconference conducted at the meeting of the International Communication Association, Chicago.

Jablin, F. M. (1987). Organizational entry, assimilation, and exit. In Jablin, F. M., Putnam, L. L., Roberts, K. H., \& Porter, L. W. (Eds.), Handbook of organizational communication: An interdisciplinary perspective (pp. 679-740). Beverly Hills: Sage.

Jablin, F. M., \& Krone, K. J. (1987). Organizational assimilation. In Berger, C. R., \& Chaffee, S. H. (Eds.), Handbook of communication science (pp. 711-746). Beverly Hills, CA: Sage.

Katz, R. (1980). Time and work: Toward an integrative perspective. In B. M. Staw \& L. L. Cummings (Eds), Research in Organizational Behavior, 2 (pp. 81-127), Greenwich, CT: JAI Press.

Kleinman, S. (1983). Collective matters as individual concerns: Peer culture among graduate students. Urban Life, 12, 203-225.

Kram, K. E. (1985). Mentoring at work: Developmental relationships in organizational life. Glenview, IL: Scott, Foresman \& Co.

Kreps, G. L. (1983). Using interpretive research: The development of a socialization program at RCA (pp. 243-256). In Putnam, L. L., \& Pacanowsky, M. E. (Eds.), Communication and organizations: An interpretive approach. Beverly Hilis: Sage.

Lester, R. E. (1986). Organizational culture, uncertainty reduction and the socialization of new organizational members. In $\mathrm{S}$. Thomas (Ed.), Culture and communicationMethodology, behavior, artifacts, and institutions: Selected proceedings of the 5 th International Conference on Culture and Communication, Temple University (pp. 105-113). Norwood, NJ: Ablex.

Lloyd, S. (1983). A typological description of premarital relationship dissolution. Unpublished doctoral dissertation, Oregon State University.

Lloyd, S., and Cate, R. (1984). Attributions associated with significant turning points in premarital relationship development and dissolution. Paper presented at the Second International Conference on Personal Relationships, Madison, WI.

Louis, M. R. (1980). Surprise and sense making: What newcomers experience in entering unfamiliar organizational settings. Administrative Science Quarterly, 25, 226-251.

Lyman, L. M., \& Scott, M. B. (1970). A sociology of the absurd. New York: Meredith.

Miell, D. (1984). Strategies in information exchange in developing relationships: Evidence for a unique relational context. Paper presented at the Second International Conference on Personal Relationships, Madison, WI.

Miles, M. B., \& Huberman, A. M. (1984). Qualitative data analysis: A Sourcebook of new methods. Beveriy Hills, CA: Sage.

Ouchi, W. G. (1981). Theory Z: How American business can meet the Japanese challenge. Reading, MA: Addison-Wesley. 
Pavalko, R. M., \& Holley, J. W. (1974). Determinants of professional self-concept among graduate students. Social Science Quarterly, 55, 462-477.

Reichers, A. E. (1987). An interactionist perspective on newcomer socialization rates. Academy of Management Review, 12, 278-287.

Rosen, B. C., \& Bates, A. D. (1967). The structure of socialization in graduate school. Sociological Inquiry, 37, 71-84.

Schein, E. H. (1971). The individual, the organization, and the career: A conceptual scheme. Journal of Applied Behavioral Science, 7, 401-426.

Simon, H. (1976). Administrative behavior: A study of decision-making processes in administrative organizations (3rd ed.). New York: Academic Press.

Stohl, C. (1986). The role of memorable messages in the process of organizational socialization. Communication Quarterly, 34, 231-249.

Surra, C. (1984). Attributions about changes in commitment Variations by courtship style. Paper presented at the Second International Conference on Personal Relationships, Madison, WI.

Tompkins, P., \& Cheney, G. (1985). Communication and unobtrusive control in contemporary organizations. In R. McPhee and P. Tompkins (Eds.), Organizational communication: Traditional themes and new directions (pp. 179-210). Beverly Hills, CA: Sage.

Tompkins, P. K., Fisher, J. Y., Infante, D. A., \& Tompkins, E. L. (1975). Kenneth Burike and the inherent characteristics of formal organizations: A field study. Speech Monographs, 42, 135-142.

Van Maanen, J. (1975). Police socialization: A longitudinal examination of job attitudes in an urban police department. Administrative Science Quarterly, 20, 207-228.

Van Maanen, J. (1976). Breaking in: Socialization to work. In R. Dubin (Ed.), Handbook of work, organization and society (pp. 67-120). Chicago: Rand McNally.

Wanous, J. (1980). Organizational entry: Recruitment, selection, and socialization of newcomers. Reading, MA: Addison-Wesley.

Watzlawick, P., Beavin, J., \& Jackson, D. (1967). Pragmatics of human communication: A study of interactional patterns, pathologies, \& paradoxes. New York: W. W. Norton.

Weiss, C. S. (1981). The development of professional role commitment among graduate students. Human Relations, 34, 13-31.

Wilson, C. E. (1984, May). A communication perspective on socialization in organizations. Paper presented at the meeting of the International Communication Association, San Francisco.

Wilson, C. E. (1986, November). Organizational socialization, uncertainty reduction and communication networks. Paper presented at the meeting of the Speech Communication Association, Chicago. 
Copyright of Western Journal of Speech Communication: WJSC is the property of Western States Communication Association and its content may not be copied or emailed to multiple sites or posted to a listserv without the copyright holder's express written permission. However, users may print, download, or email articles for individual use. 